\title{
REMOÇÃO DE NITROGÊNIO AMONIACAL DE LIXIVIADO DE ATERRO SANITÁRIO POR STRIPPING
}

\author{
REMOVAL OF AMONIACAL NITROGEN FROM LANDFILL LEACHATE BY \\ STRIPPING
}

\author{
Elson Mendonça Felici'; Arthur Pereira dos Santos'; Sandra Márcia \\ Cesário Pereira da Silva²; Emília KiyomiKuroda²
}

${ }^{1}$ UNOESTE - Universidade do Oeste Paulista

FEPP - Faculdade de Engenharia de Presidente Prudente

e-mail: elson@unoeste.br

${ }^{2}$ UEL - Universidade Estadual de Londrina

CTU - Centro de Tecnologia e Urbanismo

RESUMO -O processo de stripping de amônia, air stripping ou arraste pelo ar, é uma forma de tratamento utilizado para remoção de $\mathrm{N}$ amoniacal em diversos tipos de efluentes. Nesse sentido, esse trabalho objetivou avaliar a remoção de nitrogênio amoniacal de lixiviado de aterro sanitário por stripping. O trabalho foi realizado com a alimentação do sistema do tipo intermitente (batelada) e durante o processo foram monitorados diariamente: $\mathrm{pH}$, oxigênio dissolvido, alcalinidade, temperatura, $\mathrm{N}$-amoniacal, nitrito e nitrato. As análises de NKT foram realizadas uma vez a cada dois dias. Os resultados apresentaram tempo de detenção nos tanques de stripping entre 17 e 25 dias e remoção de nitrogênio amoniacal entre 48 e 59\%. Pode-se concluir que a remoção de amônia por stripping, não foi tão eficiente quanto a ingestão de microbolhas e que o tempo de detenção acima de 17 dias, pode ser uma dificuldade operacional para implantação do sistema em escala real.

Palavras-chave: stripping; amônia; lixiviado.

Recebido em: 02/06/2018 Revisado em: $14 / 12 / 2018$ Aprovado em: 18/12/2018
ABSTRACT -The process of stripping ammonia or air stripping, is a form of treatment used to remove ammoniacal nitrogen used in various types of effluents. In this sense, this research aimed to evaluate the removal of ammoniacal nitrogen by stripping from landfill leachate. The experiment was carried out with intermittent (batch) type system feeding and during the process were daily monitored: $\mathrm{pH}$, dissolved oxygen, alkalinity, temperature, $\mathrm{N}$-ammoniacal, nitrite and nitrate. NKT analyzes were performed once every two days. The results showed detention time in stripping tanks between 17 and 25 days and removal of ammoniacal nitrogen between 48 and 59\%. We concluded that ammonia removal by stripping was not as efficient as the ingestion of microbubbles and that the holding time over 17 days could be an operational difficulty for implantation of the system in real scale.

Keywords: stripping; ammonia; landfill leachate 


\section{INTRODUÇÃO}

O lixiviado de aterro de resíduos sólidos urbanos, também denominado chorume, é produzido pela decomposição físico-química e biológica dos resíduos depositados em um aterro e pela solubilização de componentes do lixo na água. De forma geral, é um líquido de cor escura, odor desagradável, que apresenta altas concentrações de substâncias húmicas e nitrogênio amoniacal (WISZNIOWSKI et al. 2006; KJELDSEN et al., 2002).

Nesse sentido, o processo de stripping de amônia, air stripping ou arraste pelo ar, é uma forma de tratamento utilizado para remoção de $\mathrm{N}$-amoniacal que consiste na volatilização da amônia livre $\left(\mathrm{NH}_{3}\right)$ presente na fase líquida, (neste caso o lixiviado), por meio do contato com o ar. Esse contato do líquido com o ar pode ser otimizado forçando a exposição do meio líquido com o meio gasoso, a partir da instalação de agitadores. De acordo com Gomes et al. (2009) dentre os processos físico-químicos, o que se revelou mais eficaz para a remoção do nitrogênio amoniacal foi o stripping de amônia.

Segundo Von Sperling (2005), à medida que a amônia livre é volatilizada, as formas de $\mathrm{N}$-amoniacal entram em um desequilíbrio momentâneo que rapidamente é restabelecido. Dessa forma, os íons amônio $\left(\mathrm{NH}_{4}{ }^{+}\right)$liberam íons $\mathrm{H}+$ formando novas moléculas de amônia livre. Devido ao sistema de tamponamento bicarbonato-gás carbônico, a liberação de íons $\mathrm{H}+$ não gera acidez instantaneamente.

De acordo com Baird (2000), em soluções aquosas, o $\mathrm{N}$-amoniacal pode ser encontrado na forma de amônia livre (NH3), ou também na forma de íons amônio ( $\mathrm{NH} 4+$ ). Fatores como o pH e a temperatura estão diretamente relacionados com o equilíbrio entre essas formas de $\mathrm{N}$-amoniacal. Esta relação é expressa pela equação 1 :

$$
\left[\mathrm{NH}_{3}\right]=\frac{\left[\left(\mathrm{NH}_{3}+\mathrm{NH}_{4}^{+}\right)\right]}{1+10^{p K a-p H}}
$$

Onde:
- $[\mathrm{NH} 3+\mathrm{NH} 4+]=$ concentração total de $\mathrm{N}$ amoniacal;

- Ka = constante de ionização máxima para a amônia;

- pKa $=4 \times 10^{-8} \times T^{3}+9 \times 10^{-5} \times T^{2}-0,0356 x t+$ 10,072;

- $\mathrm{T}$ = temperatura em ${ }^{\circ} \mathrm{C}$.

Como mostrado na equação (1), a elevação do $\mathrm{pH}$ e da temperatura desloca o equilíbrio entre as formas de $\mathrm{N}$-amoniacal, prevalecendo a amônia livre, como mostrado na Figura 1. Quanto mais elevado o pH, maior o percentual de amônia livre.

Figura 1. Porcentagem de amônia livre em função do $\mathrm{pH}$, para diferentes temperaturas

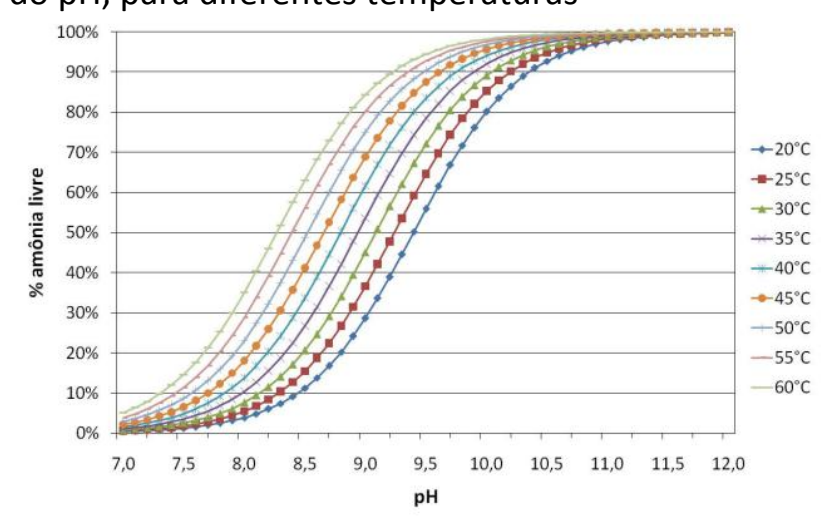

Fonte: (Hossaka, 2008).

O processo de stripping de amônia é fortemente influenciado pela temperatura. Para Metcalf e Eddy (2003), em climas mais frios, a eficiência do sistema cai significativamente. De acordo com Felix e Cardoso (2004) isso se deve ao fato de que à medida que a temperatura aumenta a amônia vai se torna mais volátil. Segundo os autores, a amônia pode ser facilmente removida da água por meio do processo de fervura.

Infelizmente, no caso do lixiviado, esse procedimento não é tão simples de ser realizado por conta dos altos volumes gerados em aterro sanitário. Contudo, buscando-se investigar essa questão, Souto (2009) realiz $\cdot \cdot$ ue o lixiviado foi (Equação 1) $\exists$ em béqueres de 100 e $300 \mathrm{ml}$. 0 aquecimento até a fervura provocou uma intensa 
formação de espuma, e após 30 minutos de fervura, alcançou-se apenas $30 \%$ de remoção do nitrogênio amoniacal.

Hossaka (2008) monitorou um tanque de stripping com volume de 1000 litros com alimentação intermitente de lixiviado proveniente do mesmo aterro de resíduos sólidos que foi utilizado no presente estudo, e alcançou uma remoção de $52 \%$ de nitrogênio amoniacal, para tempo de detenção hidráulica de 19 dias, com temperatura variando entre 18 e 25 e pH entre 8,0 e 8,5 . $O$ autor também monitorou um sistema de stripping constituído de dois tanques de 250 litros, com misturador mecânico, operado em batelada, para as mesmas condições de $\mathrm{pH}$ e temperatura. Foi constatado $50,5 \%$ de remoção de nitrogênio amoniacal com tempo de detenção hidráulica de 11 dias.

Calli et al. (2005) alcançaram remoção de aproximadamente $94 \%$ de $\mathrm{N}$-amoniacal, a temperatura de $20^{\circ} \mathrm{C}$ e $\mathrm{pH}$ ajustado para 11 durante 12 horas, com processo de stripping de amônia, utilizando difusores capazes de injetar microbolhas de ar.

Pi et al. (2009), conseguiram $88,6 \%$ de remoção de amônia do lixiviado exposto a $\mathrm{pH}$ 11 e temperatura de $50^{\circ} \mathrm{C}$ durante 18 horas utilizando processos de stripping de amônia por injeção de ar.

Uma questão que deve ser investigada, principalmente para projetos de tanques de stripping de amônia em escala real, é a liberação de amônia na atmosfera e suas possíveis causas ao meio ambiente e à saúde humana.

Nesse sentido, o objetivo desse estudo foi avaliar a remoção de nitrogênio amoniacal de lixiviado de aterro utilizando o processo de stripping.

\section{METODOLOGIA}

O sistema de air stripping estudado foi construído em uma etapa prévia de um sistema piloto que consistiu no tratamento biológico em batelada de lixiviado de aterro sanitário. $\mathrm{O}$ tratamento biológico utilizou o processo de lodo ativado e foi operado por processo aeróbio para nitrificação. Em seguida, ocorreu um processo anóxico para desnitrificação por via curta mediante adição de etanol como fonte externa de carbono.

Para a etapa descrita utilizou-se um sistema em escala piloto, semelhante ao desenvolvido por Hossaka (2008), apresentado na Figura 2. A alimentação do sistema foi do tipo intermitente, também conhecida como batelada. Para fins de comparação, foram monitoradas três bateladas.

Figura 2. Esquema do sistema de tratamento de lixiviado de aterro sanitário

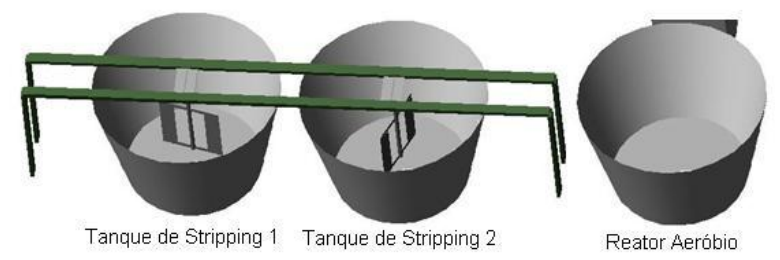

O lixiviado utilizado nesse estudo foi coletado no aterro controlado de Londrina PR, por meio de caminhões-tanques preparados para não haver alterações na composição do lixiviado.

Nos tanques de stripping foram monitorados diariamente: $\mathrm{pH}$, oxigênio dissolvido, alcalinidade, temperatura, Namoniacal, nitrito e nitrato. As análises de NKT foram realizadas uma vez a cada dois dias. Além das análises diárias, eram realizados os ensaios de DBO5, DQO e sólidos totais, sempre quando os tanques de stripping recebiam o lixiviado bruto.

Destaca-se que o objetivo desta pesquisa foi monitorar a série nitrogenada e que os outros parâmetros serviram apenas como parâmetros operacionais do sistema. Ressalta-se ainda que o lixiviado tratado não sofreu ajustes de temperatura e $\mathrm{pH}$. 
Tabela 1. Parâmetros investigados e metodologia utilizada durante os experimentos

\begin{tabular}{c|c|c}
\hline Parâmetro & Referência & Método \\
\hline $\begin{array}{c}\text { N- } \\
\text { Amoniacal }\end{array}$ & $4500-N H 3$ B e C & $\begin{array}{c}\text { Destilação e } \\
\text { Titulação }\end{array}$ \\
\hline NKT & $4500-$ Norg B e C & $\begin{array}{c}\text { Micro- } \\
\text { Kjeldhal }\end{array}$ \\
\hline Nitrito & $4500-N O 2-$ B & $\begin{array}{c}\text { Método } \\
\text { colorimétrico }\end{array}$ \\
\hline Nitrato & Cataldo (1975) & $\begin{array}{c}\text { Método do } \\
\text { ácido salicílico }\end{array}$ \\
\hline
\end{tabular}

Fonte: APHA, AWWA, WEF (2005)

Tabela 2. Equipamentos utilizados nas análises laboratoriais

\begin{tabular}{|c|c|}
\hline Parâmetro & Equipamentos utilizados \\
\hline $\begin{array}{c}\mathrm{N}- \\
\text { Amoniacal }\end{array}$ & $\begin{array}{l}\text { - pHmetro: HANNA HI } 9321 \\
\text { - Agitador: FISATOM } 761 \\
\text { - Titulador: METROHM } 20 \mathrm{ml} \\
\text { - Destilador: MARCONI MA } 036\end{array}$ \\
\hline NKT & $\begin{array}{l}\text {-pHmetro: HANNA HI } 9321 \\
\text {-Agitador: FISATOM } 761 \\
\text {-Titulador: METROHM } 20 \mathrm{ml} \\
\text {-Destilador: MARCONI MA } 036 \text { - } \\
\text { Bloco digestor: TECNAL 008750- } \\
04\end{array}$ \\
\hline Nitrito & $\begin{array}{l}\text {-Espectrofotômetro: Spectronic } \\
20 \text { GENESYS }\end{array}$ \\
\hline Nitrato & $\begin{array}{l}\text {-Espectrofotômetro: Spectronic } \\
20 \text { GENESYS }\end{array}$ \\
\hline
\end{tabular}

Figura 3. Tanques de Stripping de Amônia

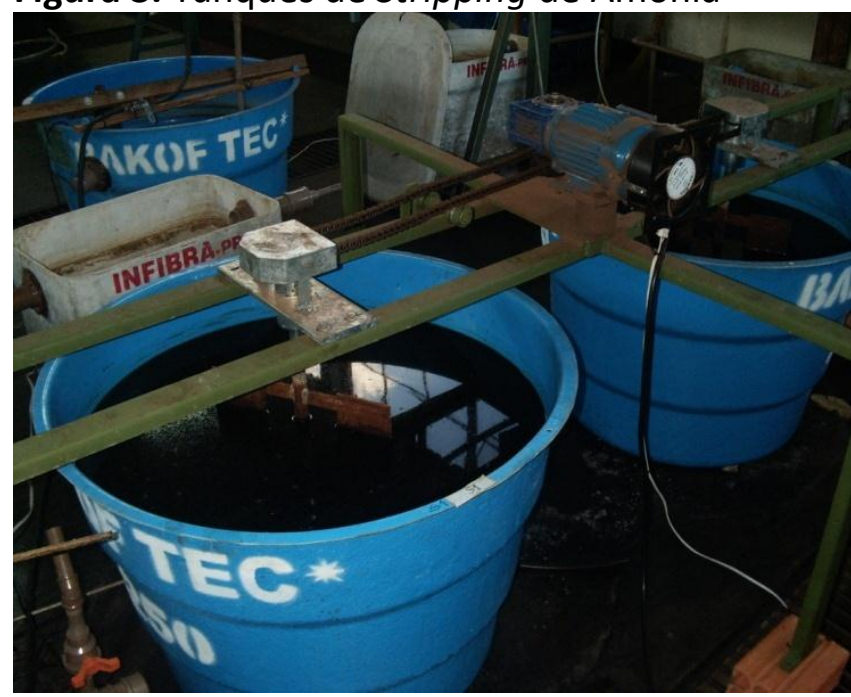

Nos tanques de stripping, foram instaladas duas pás metálicas, ligadas a um motor, que promoveram a mistura completa do tanque sem provocar aeração. Para os tanques, foram utilizados dois reservatórios de fibra de vidro de volume útil de $250 \mathrm{~L}$ cada, com diâmetro variável ao longo de sua altura, mostrado na Figura 3 . Os tanques de stripping possuíam as seguintes dimensões: $0,65 \mathrm{~m}$ de diâmetro da base; 0,90 $\mathrm{m}$ de diâmetro do topo e; 0,67 m de altura.

\section{RESULTADOS E DISCUSSÃO}

A Figura 4 mostra a evolução da série nitrogenada ao longo dos dias em cada batelada. 
Figura 4. Evolução da série nitrogenada na fase de stripping.

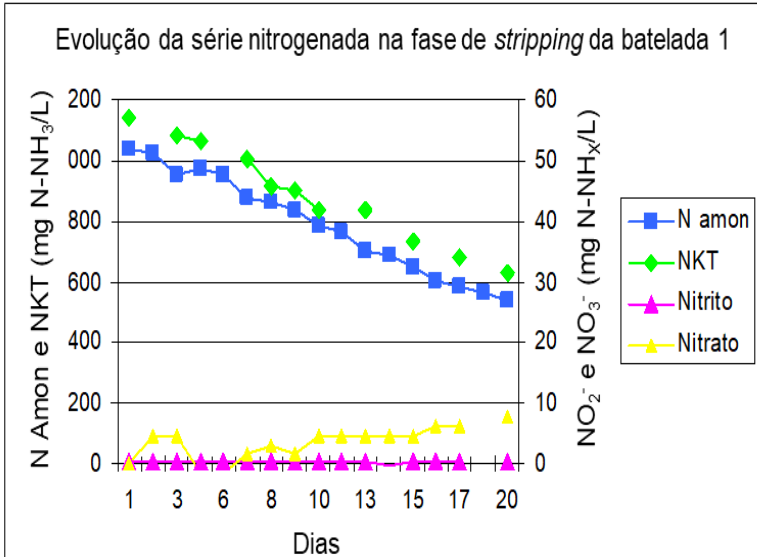

Evolução da série nitrogenada na fase de strippina da batelada 2

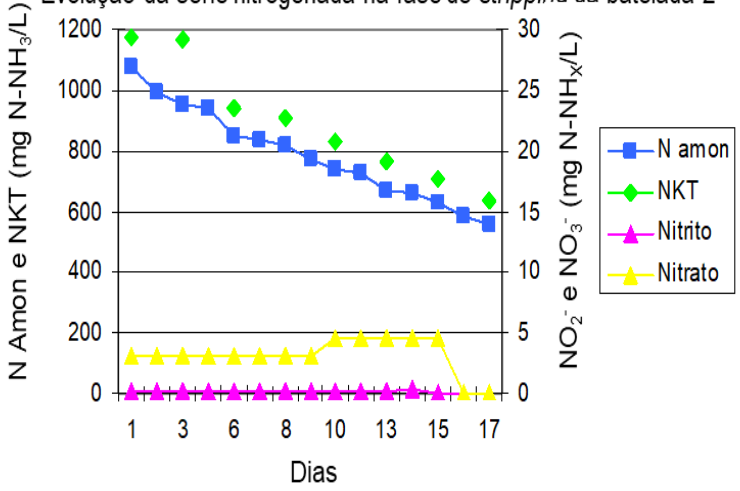

Evolução da série nitrogenada na fase de stripping da batelada 3

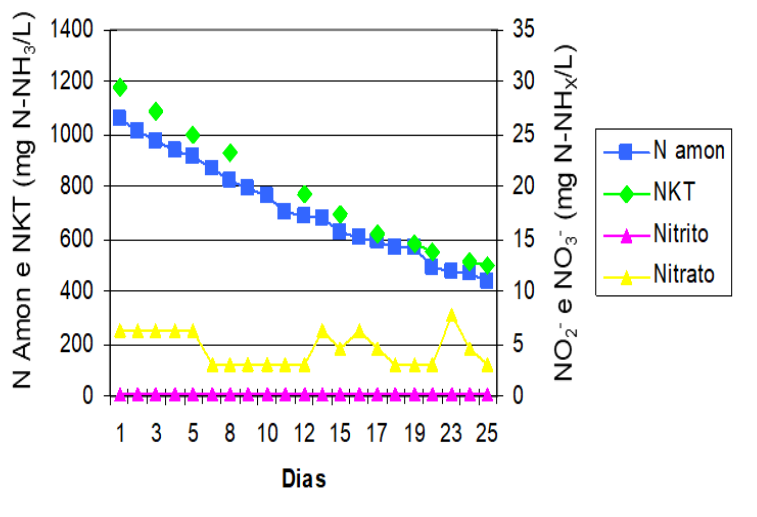

O tempo de detenção nos tanques de stripping permaneceu entre 17 e 25 dias, com remoção de nitrogênio amoniacal variando entre 47 e $58 \%$. Nos tanques de stripping não ocorreu à formação de nitrito e nitrato. Resultados semelhantes foram encontrados por Hossaka (2008) durante o monitoramento de um sistema semelhante.

Os resultados mostraram que os valores de nitrito e nitrato sempre estiveram próximos de $5 \mathrm{mg} \mathrm{NO}{ }^{\mathrm{x}-} / \mathrm{L}$, mantendo-se constante durante todo o monitoramento. Pode-se dizer que a perda de amônia por stripping foi responsável pelo decaimento de $\mathrm{N}$-amoniacal, já que não ocorreu a transformação dessa forma de nitrogênio em nitrito ou nitrato, corroborando com as conclusões de Pi et al. (2009).

Observou-se ainda, que a taxa de decaimento de nitrogênio amoniacal permaneceu constante durante todo o processo. Resultados semelhantes foram descritos por Souto (2009).

Em relação à quantidade de amônia removida, o sistema não foi mais eficiente do que aqueles que utilizaram difusores capazes de injetar microbolhas de ar. Calli et al. (2005) e Pi et al. (2009) atingiram respectivamente $94 \%$ e $88 \%$ de remoção de amônia com tempos de detenção menores do que aqueles apresentados neste trabalho.

Resultados de remoção de nitrogênio amoniacal maiores foram obtidos quando os valores de $\mathrm{pH}$ e temperatura foram ajustados (MORAVIA, 2007; VEIGA, et. al., 2006). Sendo assim, é possível ressaltar que a temperatura e $\mathrm{o}$ pH são parâmetros influenciam diretamente a eficiência de remoção de nitrogênio amoniacal por stripping, conforme salientado por Metcalf e Eddy (2003).

\section{CONSIDERAÇÕES FINAIS}

Apesar do experimento conduzido atingir índices de remoção de nitrogênio amoniacal entre 48 e $59 \%$, pode-se concluir que a remoção de amônia por stripping, não é mais eficiente do que à técnica de ingestão de microbolhas, conforme os resultados de outras pesquisas (CALLI et al., 2005; PI et al., 2009).

Além disso, conclui-se que o tempo de detenção acima de 17 dias, representa uma dificuldade operacional para a implantação do sistema em escala real.

Por fim, sugere-se que trabalhos futuros, ao utilizar o mesmo sistema piloto e a mesma técnica de tratamento, avaliem diretamente a influência da temperatura e do pH na remoção de nitrogênio amoniacal. 


\section{REFERÊNCIAS}

APHA, AWWA, WEF . Standards Methods for the Examination of Water e Wastewater, 21. ed. Washington. D.C, 2005.

BAIRD, C. Environmental chemistry.2nd ed. New York: W. H. Freeman, 2000.

CALLI, B.; MERTOGLU, B.; INANC, B. Landfill leachate management in Istanbul: applicationsand alternatives. Chemosphere, v. 59, p. 819-829, 2005. https://doi.org/10.1016/i.chemosphere.2004.10. $\underline{064}$

CATALDO, D. A.; HAROON, M.; SCHRADER, L. E.; YOUNGS, V. L. Rapid colorimetric determination of nitrate in plant tissue by nitration of salicylic acid. Communications in Soil Science andPlantAnalysis, v. 6, p. 71-80, 1975. https://doi.org/10.1080/00103627509366547

FELIX, E. P.; CARDOSO, A. A. Amônia (NH3) atmosférica: fontes, transformação, sorvedouros e métodos de análise. Química Nova, v. 27, n.1, p. 123-130, 2004. https://doi.org/10.1590/S0100$\underline{40422004000100022}$

GOMES, L.P. (coord) Estudos de caracterização e tratabilidade de lixiviados de aterros sanitários para as condições brasileiras. Projeto PROSAB. Rio de Janeiro: ABES, 2009.

HOSSAKA, A. L. Tratamento biológico de lixiviados de aterro sanitário, utilizando como pré-tratamento a remoção parcial de Namoniacal por stripping. 2008. Dissertação (Mestrado em Engenharia de Edificações e Saneamento) - Universidade Estadual de Londrina. Centro de Tecnologia e Urbanismo. Londrina, 2008.

KJELDSEN, P.; BARLAZ, M. A.; ROOKER, A. P.; BAUN, A.; LEDIN, A.; CHRISTENSEN, T. Present and Long-Term Composition of MSW Landfill Leachate: A Review. Environmental Science and Technology., v. 32, n.4, p. 297-336, 2002. https://doi.org/10.1080/10643380290813462

METCALF E EDDY. Waste Engineering. New York: McGraw Hill, 2003.
MORAVIA, W. G. Estudo de Caracterização, Tratabilidade e Condicionamento de Lixiviados visando Tratamento por Lagoas. 2007. Dissertação (Mestrado) - Programa de PósGraduação em Saneamento, Meio Ambiente e Recursos Hídricos. Escola de Engenharia. Universidade Federal de Minas Gerais, Belo Horizonte, 2007.

PI, K. W.; LI, Z.; WAN, D. J.; GAO, L. X. Pretreatment of municipal landfill leachate by a combined process. ProcessSafetyand Environmental Protection, v. 87, p. 191-196, 2009.

https://doi.org/10.1016/i.psep.2009.01.002

SOUTO, G. D. B. Lixiviado de aterros sanitários brasileiros - estudo de remoção do nitrogênio amoniacal por processo de arrastem com ar ("stripping"). 2009. . Tese (Doutorado) - Escola de Engenharia de São Carlos, Universidade de São Paulo, São Carlos, 2009.

VEIGA, A. A.; CARDILLO, L.; YOKOYAMA, L.; CAMPOS, J.C. Remoção de Amônia em Chorume por Arraste de Ar. In: SIMPÓSIO ÍTALOBRASILEIRO DE ENGENHARIA AMBIENTAL E SANITÁRIA, 8., 2006, Fortaleza. Anais [...]. Fortaleza, 2006.

VON SPERLING, M. Introdução à qualidade das águas e ao tratamento de esgotos. 3. ed. Belo Horizonte: DESA-UFMG, 2005.

WISZNIOWSKI, J.; ROBERT, D.; SURMACZGORSKA, J.; MIKSCH, K.; WEBER, J.V. Landfill leachate treatment methods: $A$ review. Environmental Chemistry Letters, v. 4, p.51-61, 2006. https://doi.org/10.1007/s10311-005-0016$\underline{z}$ 